\title{
Creating Community
}

\author{
Wendy C. Budin, PhD, RN-BC, LCCE, FACCE
}

\begin{abstract}
In this column, the editor of The Journal of Perinatal Education describes ways that Lamaze International is helping to create a community for those who share a common interest in promoting, supporting, and protecting natural, safe, and healthy childbirth. The editor also describes the contents of this issue, which offer a broad range of resources, research, and inspiration for childbirth educators in their efforts to promote normal birth.
\end{abstract}

The Journal of Perinatal Education, 18(4), 1-3, doi: 10.1624/105812409X474645

Keywords: normal birth, natural birth, safe birth, healthy birth, childbirth education

According to Wikipedia (2009), a "community" has traditionally been defined as "a group of interacting people living in a common location" (para. 2). Although "the word is often used to refer to a group that is organized around common values and social cohesion within a shared geographical location..., [s]ince the advent of the Internet, the concept of community no longer has geographical limitations, as people can now virtually gather in an online community and share common interests regardless of physical location" (para. 2 and 4).

Never before has there been a greater opportunity for individuals who share a common interest in promoting, supporting, and protecting natural, safe, and healthy chidlbirth to come together as one virtual community. Recently, Lamaze International launched a redesigned Web site with interactive resources for new and expectant parents as well as childbirth professionals. Whether your goal is to join a community of parents, educators, or birth advocates or keep up to date with the latest research about pregnancy, birth, and beyond, there is something for everyone on the Lamaze Web site.

A link to the Lamaze online community includes features such as "Ask an Expert," where individuals with questions can join in discussion with Henci Goer, an expert in obstetric research, and learn more about how to achieve a safe and healthy birth. With "Twitter for Expectant Parents," one can follow Lamaze online and keep up to date with the latest birth talk on the Internet. "Twitter for Childbirth Educators" allows health professionals to follow Lamaze online and stay current about the latest birth news, information, and events. Link to the Giving Birth with Confidence blog and hear the authors of The Official Lamaze Guide muse about Wendy C. Budin

birth, family, current events, and a whole lot more. Editor Subscribe to Science \& Sensibility, a research blog about pregnancy, birth, and beyond. Lamaze is also now on Facebook, linking a community of parents, educators, and other birth advocates in the most widely used social network worldwide. The online "Lamaze Discussion Forums" allow interested individuals to join various Lamaze special interest groups or discuss upcoming events. Whatever the reason, the "Lamaze Discussion Forums" are the place for childbirth educators to connect.

I encourage you to get involved with this exciting community. Lamaze International is committed to positively impacting the health and well-being of

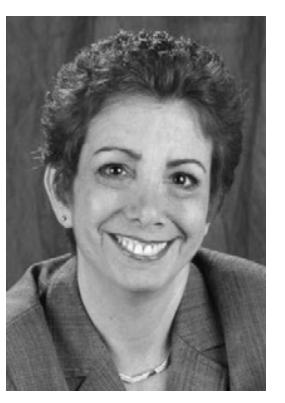

We invite readers to respond to the contents of this issue or share comments on other topics related to promoting natural birth. Responses will be published as a letter to the editor. Please send comments to Wendy Budin, Editor-in-Chief (wendy. budin@nyu.edu).

W

Visit the Lamaze International Web site at www.lamaze.org 
Never before has there been a greater opportunity for individuals

who share a common interest in promoting, supporting, and

protecting natural, safe, and healthy childbirth to come together as

one virtual community.

women as they prepare for childbirth. Lamaze provides access to pregnancy, birth, and parenting support and resources for families, and enables Lamaze members and other birth advocates to support women in their local communities. If you are not yet a member of Lamaze International, I urge you to advance your career by becoming a member of the leading organization that promotes natural, safe, and healthy birth. Take full advantage of the many resources available to members. Members gain access to the newest information through continuing education opportunities, professional development resources, and publications including The Journal of Perinatal Education. Be a part of the movement to serve as a contemporary, credible source of education and information for birthing mothers around the world. There are a number of volunteer opportunities to engage with the international organization and make an impact on mothers and babies around the world. Join or start a Birth Network in your local community. Birth Networks are independent, grassroots advocacy organizations promoting evidence-based maternity care to improve birth outcomes. These are just a sample of the many volunteer opportunities and membership benefits.

Our members and volunteers are the weave that make our organization strong. Interested and committed people who share a common interest in promoting natural, safe, and healthy birth are the fabric of our community. You can make a difference simply by sharing your self, your interest, and your talents.

The content of all JPE issues published since October 1998 are available on the journal's Web site (www. ingentaconnect.com/ content/lamaze/jpe). Lamaze International members can access the site and download free copies of JPE articles by logging on at the "Member Center" link on the Lamaze Web site (www.lamaze.org).

\section{IN THIS ISSUE}

Continuing The Journal of Perinatal Education's mission to promote natural birth, in this issue's "Celebrate Birth!" column, authors Kate Burkhardt Brandt and her doula Patricia Burkhardt, who is also a midwife, describe the strategies used during pregnancy and labor to maximize the success of a vaginal birth after a previous cesarean surgery.

\section{Our members and volunteers are the weave that make our}

In a thought-provoking guest editorial, Susan Hodges explores the question of whether laboring and birthing women are treated abusively in the hospital. Although seldom recognized as abuse or violence against women, bullying and medical treatments under false pretenses constitute abuse, even in a hospital, and this abuse is a basic human rights issue that needs attention. Hodges proposes that naming the problem is a first step. Learning to recognize abuse and take effective action, and understanding the legal requirements for "informed consent" can help, but ending abuse will require systemic change.

In their article "Paternal Fears of Childbirth," Suzanne Hanson, Lauren Hunter, Jill Bormann, and Elisa Sobo summarize the research findings on paternal childbirth fears and recommend topics for future study. According to these authors, most prior studies on paternal childbirth fears have been exploratory or descriptive, conducted outside of the United States, and focused mainly on White, firsttime fathers. Identified fears include harm to the mother or newborn, partner pain, feelings of helplessness, lack of knowledge, and fear of high-risk intervention. Fathers often report that childbirth classes are not helpful and, in some cases, even increase their fears. Some fathers view birth as traumatic, changing their perception and relationship with their partner. Fathers also voice the need for more information and for reassurance that they are doing the right things for their partner during childbirth.

According to U.K. author Mary Nolan, studies of childbirth education have universally failed to take into account the quality of the education provided to women and their families and whether its style of delivery meets women's preferences and needs. Nolan's research sought to determine which educational approaches are most welcomed by women and most helpful to them in learning about labor, birth, and early parenting. In her article, "Information Giving and Education in Pregnancy," Nolan presents a systematic survey of peer-reviewed studies on antenatal education, published in English from 1996-2006, which sought women's views and experiences. Findings confirm women's preference for a small-group learning environment in which they can talk to each other as well as the educator and can relate information to their individual circumstances.

Michele Ondeck and Judith Focareta share an interesting article about environmental hazards and valuable resources for childbirth educators. The 
authors describe how hazardous chemicals have been found in cord blood, placenta, meconium, and breastmilk samples. Childbirth educators are encouraged to inform themselves about these hazards in order to inform childbearing families to take preventive action and explore alternative behaviors to reduce exposure to environmental hazards.

In her "Navigating the Maze" column, Judith Lothian discusses persuasion as a way to change women's ideas about safe, healthy birth. The relationship between persuasion and choice is discussed, and the differences between presenting information and persuading women that natural birth is the safest and healthiest way to give birth are explored.

In this issue's "Tools for Teaching" column, "From Psychoprophylactic to Orgasmic Birth," Barbara Hotelling reflects on the assumptions held by early childbirth educators that were valid when psychoprophylactic birth became available. She articulates how educators and health-care providers have changed their assumptions about birth as they have learned more from the midwifery model of care, how women want to give birth, and how capable the body is to give birth. Suggestions are provided to help educators, who must now emphasize the synchrony of hormones that facilitates birth, the Sphincter Law, and the sharing of woman-to-woman stories throughout the generations if birth is to be set in its rightful place-in the hands of the mothers.

In this issue's "Science \& Sensibility" column, "Deconstruction Junction: How to Separate the Good Evidence From the Bad (From the Ugly)," Amy Romano reprises recent selections from the Lamaze International research blog, Science \& Sensibility. Each selection discusses a new study that demonstrates the need to look closely at research articles to avoid being misled. Examples include new research on the effectiveness of intrapartum antibiotics for preventing early onset Group B streptococcal disease in newborns, a recent study on the incidence of infection after cesarean surgery and vaginal birth, and a new study demonstrating long-term benefits of skin-to-skin contact between the mother and infant after birth.

In this issue's "Media Reviews" column, coordinated by Teri Shilling, reviewers offer perspectives and comments on a variety of current DVDs and books that address the following topics: cultural views of labor and birth, as portrayed in the U.S. media; natural, safe, and healthy birth practices; memoirs of a midwife; a description of doula care to share with the children of expectant parents; baby behaviors; empowering women to choose the birth experience they want; making informed decisions about cesarean surgery; information and stories of hope for parents dealing with an infant in the neonatal intensive care unit; ways for parents to cope with perinatal or neonatal loss; and fathers' supportive role during the prenatal and postpartum periods. The DVDs and books reviewed in this issue's column include Laboring Under an Illusion: Mass Media Childbirth vs. The Real Things, from filmmaker Vicki Elson; Giving Birth, created and produced by Suzanne Arms and Susan Berthiaume; The Blue Cotton Gown: A Midwife's Memoir by Patricia Harman; Being Born: The Doula's Role by Jewel Hernandez, with illustrations by R. Michael Mithun; Why Babies Do That: Baffling Baby Behavior Explained by Jennifer Margulis; Your Best Birth: Know All Your Options, Discover the Natural Choices, and Take Back the Birth Experience by Ricki Lake and Abby Epstein; Understanding the Dangers of Cesarean Birth: Making Informed Decisions by Nicette Jukelevics, with foreword by Charles Mahan, MD; Your Premature Baby, produced by InJoy Birth and Parenting Videos; Almost Home: Stories of Hope and the Human Spirit in the Neonatal ICU by Christine Gleason, MD; Empty Arms: Coping with Miscarriage, Stillbirth, and Infant Death by Sherokee Ilse; and Fathers At Birth by Rose St. John.

After more than 13 years of regularly contributing her highly valued humor column, "Deb's Last Laugh," Deb Gauldin has decided it is time to pass the torch. In this issue's column titled "Deb's Last Column, But Not Her Last Laugh," Gauldin defines the term "rusty labor and delivery nurse" and passes the torch to a new generation of talented practitioners and columnists. We thank Deb Gauldin for her significant contribution to The Journal of Perinatal Education and wish her all the best with her many professional activities. We also look forward to occasional guest columns from her.

\section{REFERENCE}

Wikipedia. (2009). Community. Retrieved September 18, 2009, from http://en.wikipedia.org/wiki/Community

WENDY BUDIN is the editor-in-chief of The Journal of Perinatal Education. She is also the director of nursing research at NYU Langone Medical Center and a clinical professor at New York University, College of Nursing. She is a fellow in the American College of Childbirth Educators and is currently chair of the Lamaze International Certification Council. 